\title{
Descrição da larva de Idiataphe longipes (Odonata, Libellulidae, Trameini)
}

\author{
Barbara B. Oldrini ${ }^{1,2}$ \& Bernardo J. de A. Mascarenhas ${ }^{1}$ \\ 1. Departamento de Entomologia, Museu Nacional, Universidade Federal do Rio de Janeiro, Quinta da Boa Vista, São Cristóvão, \\ 20940-040 Rio de Janeiro, Brasil. \\ 2. Instituto de Biologia, Universidade Federal Rural do Rio de Janeiro, Rodovia BR 465, Km 7, 23890-000 Seropédica, Rio de Janeiro, \\ Brasil.
}

ABSTRACT. Description of the larva of Idiataphe longipes (Odonata, Libellulidae, Trameini). The larva of Idiataphe longipes (Hagen, 1861) is described from five exuviae with associated teneral adults collected in Concórdia Pond, Valença, Rio de Janeiro, Brazil.

KEYWORDS. Idiataphe, larva, Odonata, Libellulidae.

RESUMO. A larva de Idiataphe longipes (Hagen, 1861) é descrita com base em cinco exúvias associadas aos respectivos adultos emergidos, coletadas no Açude da Concórdia, Valença, Rio de Janeiro, Brasil.

PALAVRAS-CHAVE. Idiataphe, larva, Odonata, Libellulidae.

O gênero Idiataphe inclui quatro espécies: $I$. longipes (Hagen, 1861), I. amazonica (Kirby, 1889) e I. batesi (Ris, 1913) com registro para América do Sul e Central e I. cubensis (Scudder,1866), ocorrendo nas Américas do Norte e Central (RACENIS, 1969). A única larva descrita do gênero é de I. cubensis, identificada como Ephidatia cubensis por NEEDHAM \& FISHER (1936). Objetiva-se descrever e ilustrar a larva de último instar de Idiataphe longipes (Hagen, 1861).

\section{MATERIAL E MÉTODOS}

A larva de I. longipes é descrita com base em exúvias de último instar de quatro machos e uma fêmea, obtidas a partir de larvas coletadas entre 1998 e 2000, no Açude da Concórdia, Valença, Rio de Janeiro. O Parque Municipal do Açude da Concórdia é uma área de proteção ambiental permanente, apresenta remanescente de Mata Atlântica nativa e está situado a uma altitude de 945 metros (BAFFA, 1994).

Nas coletas foram utilizadas peneiras do tipo "handnet" com malha de $0,5 \mathrm{~mm}$. As larvas foram criadas e os adultos emergiram em laboratório, utilizando-se caixas de isopor com tampas teladas, alimentadas com larvas de Diptera (quironomídeos).

O lábio e as mandíbulas foram descritos segundo Corbet (1953) e Watson (1956), respectivamente.

Os adultos foram identificados e juntamente com as exúvias, incorporados à coleção de Insetos Aquáticos, Departamento de Entomologia do Museu Nacional, Universidade Federal do Rio de Janeiro (MNRJ).

\section{Idiataphe longipes (Hagen, 1861)} (Figs. 1-9)

Larva castanho-clara, pequena com pernas longas, delgadas e com longos espinhos abdominais (Fig. 1).
Cabeça mais larga que o tórax. Margem occipital e pós-ocular com uma fileira de pequenos espinhos; antenas com 7 antenômeros (Fig. 2), 1, 2 e 7 menores que os outros, que possuem aproximadamente o mesmo tamanho $(0,59 ; 0,59 ; 0,85 ; 0,85 ; 0,85 ; 0,7 ; 0,59)$; olhos arredondados, projetados lateralmente; lábio dobrado, alcança a base das pernas medianas; palpo labial (Fig. 3) com 5 setas, margem distal com 9 crenulações armadas com dois espinhos, um longo e um curto em cada crenulação; parte basal com 10 espinhos e margem externa lisa; premento (Fig. 4) com 8 setas, margem distal lisa, com uma elevação pronunciada na região mediana; dois espinhos na junção do premento com o palpo labial; mandíbulas com dentes incisivos obtusos (Figs. 5-6), fórmula mandibular L $12340 \mathrm{ab} / \mathrm{R} 1234 \mathrm{y}$ abd.

Tórax. Protórax arqueado, com uma fileira de espinhos; processo supracoxal muito pequeno, com tufo de pêlos; pernas longas e pálidas, providas de espinhos, a posterior maior que o comprimento do corpo; fêmur claro com espinhos diminutos; tarso com três artículos (Fig. 7); garras tarsais longas e divergentes; teca alar atingindo a metade do sexto segmento abdominal.

Abdome. Cilíndrico, espinhos laterais nos segmentos 8-9; espinhos dorsais nos segmentos 3-9 (Fig. 8): nos segmentos 3-4 pequenos, eretos e truncados, nos 5-6 robustos, pontudos, direcionados para trás, 7-9 grandes, achatados lateralmente, dirigidos para trás; apêndices (Fig. 9): epiprocto e paraprocto longos, retos e cobertos de longos pêlos; epiprocto largo na base e fortemente afilado na extremidade, ligeiramente maior que o paraprocto; cercos muito pequenos, menor que um terço do epiprocto.

Medidas, em milímetros: comprimento total 19-20; largura da cabeça 5; comprimento da cabeça 4; comprimento do tórax 5; comprimento do abdome 11 ; 

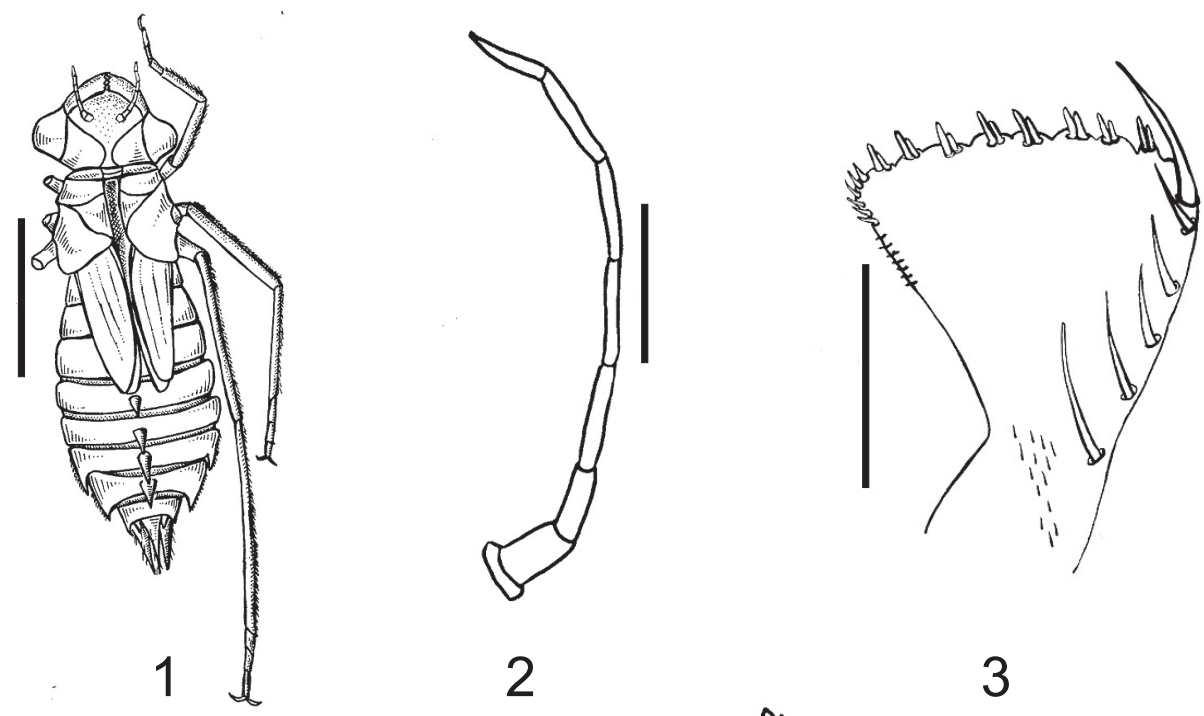

2
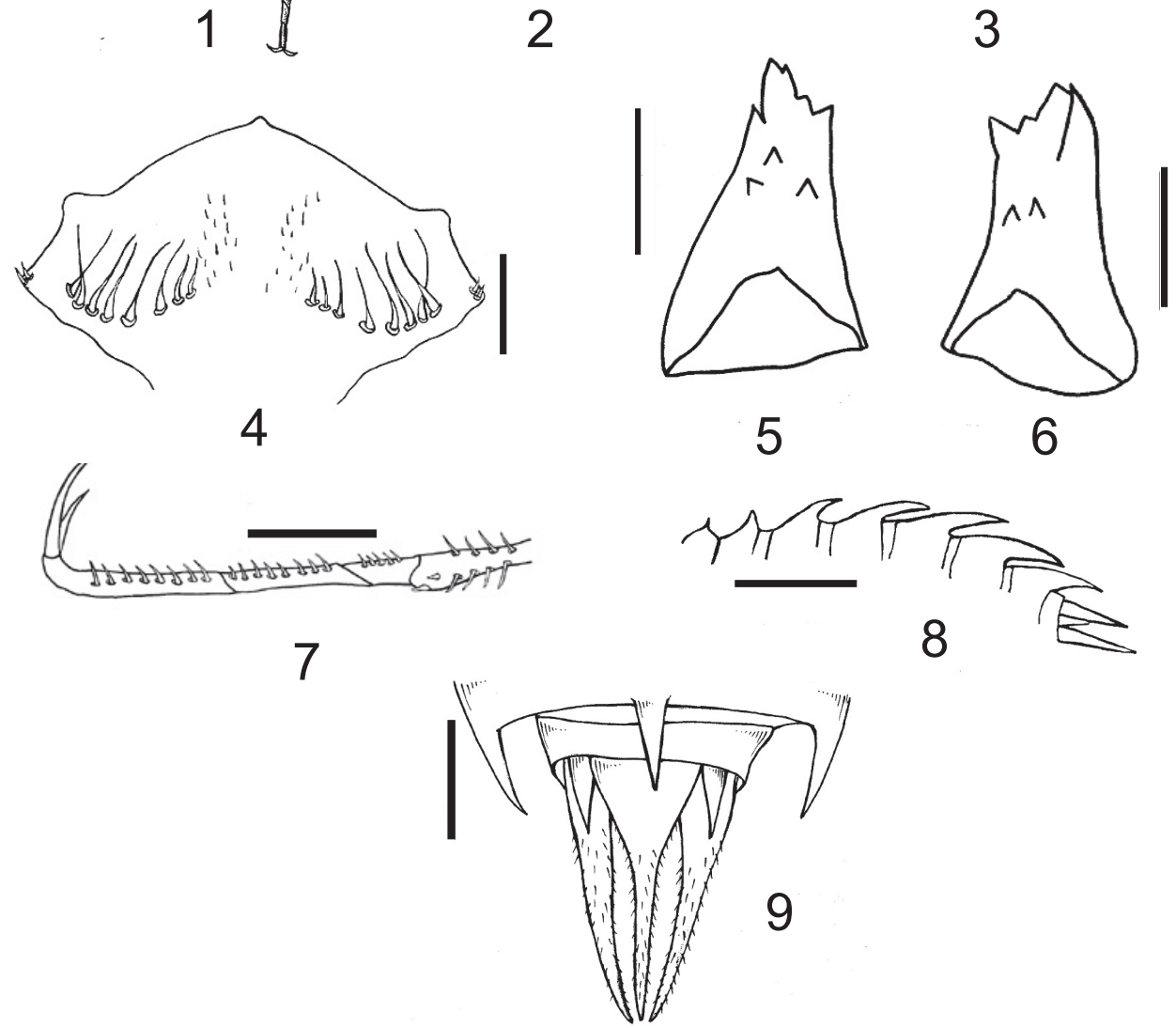

Figs. 1-9. Idiataphe longipes (Hagen, 1861), larva de último instar: 1, aspecto geral; 2, antena; 3, palpo labial, dorsal; 4, premento, ventral; 5, mandíbula direita; 6 , mandíbula esquerda; 7, tarso; 8, espinhos dorsais; 9, apêndices. Escalas: fig. 1, 10mm; figs. 2-4 e 8, $2 \mathrm{~mm}$; figs. $5-7$ e $9,1 \mathrm{~mm}$.

largura do abdome 7; fêmur I, II e III, respectivamente com 3,7; 5 e 7; tíbia I, II e III com 3,1; 4,3 e 8; epiprocto 2,9; paraprocto 2,4 ; $\operatorname{cercos} 0,7$.

Material examinado. BRASIL, Rio de Janeiro: Valença (Açude da Concórdia) O’', 13.IX.1998 (emergido em 25.X.1998); $\sigma^{2}$, 18.XII.1999 (emergido em 24.XII.1999); O', 23.II.2000 (emergido em 02.III.2000), O', 29.IV.2000 (emergido em 24.X.2000), +, 19.I.2000 (emergido em 06.II.2000), B. Mascarenhas leg. (MNRJ).

Comentários. A larva de Idiataphe longipes diferencia-se da de Idiataphe cubensis (Needham \&
Fisher, 1936) por apresentar fêmur claro e sem manchas, palpo labial com 5 setas e premento com 8 setas; enquanto que $I$. cubensis apresenta fêmur com duas manchas escuras em forma de anel, palpo labial com 6 setas e premento com 9-11setas.

Biologia. As larvas foram coletadas em ambiente lêntico com presença de salvínias e com vegetação marginal; o substrato é arenoso e rico em folhiço.

No ambiente amostrado também ocorrem as larvas de Coryphaeschna adnexa (Hagen, 1861), C. perrensi (McLachlan, 1887), Aphylla sp., Brachymesia herbida 
(Gundlach, 1889), Diastatops obscura (Fabricius, 1775), Dythemis multipunctata Kirby, 1894, Erythemis mithroides (Brauer, 1900), Erythrodiplax fusca (Rambur, 1842), Idiataphe longipes (Hagen, 1861), Macrothemis imitans Karsch, 1890, Miathyria simplex (Rambur, 1842), M. marcella (Selys, 1857), Micrathyria artemis Ris, 1911, M. catenata Calvert, 1909, M. hesperis Ris, 1911, Perithemis mooma Kirby, 1889, Planiplax phoenicura Ris, 1912, Tauriphila argo (Hagen, 1869), Acanthagrion lancea Selys, 1876, Homeoura chelifera (Selys, 1876), Ischnura capreolus (Hagen, 1861), I. fluviatilis Selys, 1876, Oxyagrion hempeli Calvert, 1909, O. microstigma Selys, 1876, Telebasis corallina (Selys, 1876), T. filiola (Perty, 1834) e Lestes sp.
Agradecimentos. À Dra. Janira Martins Costa (MNRJ) pelo apoio, sugestões e identificação do exemplar adulto.

\section{REFERÊNCIAS BIBLIOGRÁFICAS}

BAFFA, A. 1994. Valença. Segurança, clima, energia, fazendas históricas, natureza. Municípios em Revista 38:1-66.

Corbet, P. S. 1953. A terminology for the labium of larval Odonata. Entomologist 86:191-196.

Needham, J. G. \& Fisher, E. 1936. The nymphs of North America Libellulinie dragonflies. Transactions of the American Entomological Society 62:107-116.

RACENIS, J. 1969. Las especies del genero Idiataphe (Odonata: Libellulidae). Publicações Ocasionales del Museo de Ciencias Naturales 14:1-15.

Watson, M. C. 1956. The utilization of mandibular armature in taxonomic studies of anisopterous nymphs. Transactions of the American Entomological Society 81:155-202. 